\title{
Labor Market Trends for Nuclear Engineers Through 2005 1999 Update Report
}

\author{
Prepared by: \\ Analysis and Evaluation Programs \\ Oak Ridge Institute for Science and Education \\ (Managed by Oak Ridge Associated Universities for the Department of Energy) \\ Prepared for: \\ Office of Human Resources \\ U.S. Nuclear Regulatory Commission
}

October 1999

This document describes activities performed under Contract Number DE-AC05-76OR00033 between the U.S. Department of Energy and Oak Ridge Associated Universities under interagency agreement with the U.S. Nuclear Regulatory Commission.

All opinions expressed in this paper are the author's and do not necessarily reflect policies and views of the U.S. Nuclear Regulatory Commission, U.S. Department of Energy, Oak Ridge Institute for Science and Education, or Oak Ridge Associated Universities. 


\section{PART I. CURRENT JOB OPPORTUNITIES FOR NEW GRADUATES}

The current labor market in terms of job opportunities for new nuclear engineering graduates continues to improve substantially since the mid-1990s. ${ }^{1}$ Starting salaries for nuclear engineers in the nuclear energy/nuclear weapons fields ${ }^{2}$ increased $6.6 \%$ for B.S. level graduates, $5.2 \%$ for M.S. level graduates, and 5.8\% for Ph.D. level graduates between 1998 and 1999. ${ }^{3}$ These are the largest increases reported during the 1990s. Moreover, the increases in starting salaries between 1997 and 1998 for B.S. and M.S. level graduates (3.6\% and $4.6 \%$, respectively) were also larger than any increases experienced since 1991 . The improvement in job opportunities for nuclear engineering graduates resulted from a combination of two primary factors and one secondary factor.

\section{Primary Factors for Improved Job Opportunities}

- The number of nuclear engineering degrees earned annually decreased by over $45 \%$ between 1995 and $1998 .{ }^{4}$

- Nuclear engineering majors are finding many job opportunities outside of the "traditional" nuclear energy/nuclear weapons fields.

While part of the job opportunities outside of the nuclear energy/nuclear weapons fields are nuclear engineering positions in expanded fields (such as medical applications), many of these positions are not classified as nuclear engineer occupations but use the multiple skills and knowledge set provided in nuclear engineering academic programs (such as materials and metallurgy engineering, chemical engineering, mechanical engineering, and computational science).

Unfortunately, data is not collected on a systematic basis on employment of nuclear engineering majors outside of the nuclear energy/nuclear weapons fields. Thus, it is not possible to provide analytical assessments for trends in this broader labor market for new nuclear engineering graduates. However, information provided by a limited number of academic departments indicate that as many as $50 \%$ of their graduates are currently obtaining employment outside of the traditional nuclear energy/nuclear weapons fields either as nuclear engineers or in related occupational categories. ${ }^{5}$

\section{Secondary Factor for Improved Job Opportunities}

- The decline in the employment of nuclear engineers in the nuclear energy/nuclear weapons fields that occurred during the mid-1990s has stopped and, in fact, some slight increase has occurred over the last couple of years.

Some new nuclear engineering positions are occurring in the nuclear energy/nuclear weapons fields due to growth and, as attrition occurs, more of the vacated positions are being replaced rather than left empty. Part of the growth has been in the DOE laboratories, especially in weapons laboratories. Based on data from a sample of utilities, employment of nuclear engineers in nuclear electric utilities has also increased slightly and some replacement hiring is occurring.

Supply of New Graduates Versus Job Openings in Nuclear Energy/Nuclear Weapons Fields 
Currently the available supply of new nuclear engineering graduates ${ }^{6}$ appears to be less than the number of job openings for new graduates in the nuclear energy/nuclear weapons fields. This shift to a relative shortage of new graduates emerged in 1998 and is more strongly indicated in the 1999 salary data. As a result of continuing declines in the number of degrees earned, the estimated available supply of new graduates has decreased to about 275 to 325 per year while the number of job openings for new graduates is estimated to be about 300 to 350 per year. Moreover, as noted above, nuclear engineering graduates are finding many job opportunities outside of the nuclear energy/nuclear weapons fields. These other job opportunities are contributing to the increase in starting salaries for new graduates. In 1999, the percentage increase in the average entry level salary for B.S. nuclear engineering graduates was greater than the percentage increases for chemical, civil, computer, electrical, industrial, and mechanical engineering. ${ }^{7}$

Table 1. Nuclear Engineering Enrollment and Degree Trends

\begin{tabular}{|c|c|c|}
\hline Year & $\begin{array}{l}\text { (B.S.+M.S.+Ph.D.) } \\
\text { Total Degrees }\end{array}$ & $\begin{array}{l}\text { (undergrad \& grad students) } \\
\text { Total Enrollments }\end{array}$ \\
\hline 1991 & 756 & 2,865 \\
\hline 1993 & 788 & 2,828 \\
\hline 1995 & 812 & 2,204 \\
\hline 1996 & 764 & 1,838 \\
\hline 1997 & 560 & 1,520 \\
\hline 1998 & 480 & 1,399 \\
\hline
\end{tabular}

Table 2. Annual Salary Increases for Entry Level Nuclear Engineer Positions (Excludes Government, Military, Health Facilities, and Academic Institutions)

\begin{tabular}{cccccccc}
1991 & 1992 & 1993 & 1994 & 1995 & 1996 & 1997 & 1998 \\
to & to & to & to & to & to & to & to \\
1992 & $\underline{1993}$ & $\underline{1994}$ & $\underline{1995}$ & $\underline{1996}$ & $\underline{1997}$ & $\underline{1998}$ & $\underline{1999}$ \\
\hline
\end{tabular}

B.S.

$\begin{array}{llllllll}\text { Level: } & 4.3 \% & 1.8 \% & 2.5 \% & 1.6 \% & 2.1 \% & 3.1 \% & 3.6 \%\end{array}$

M.S.

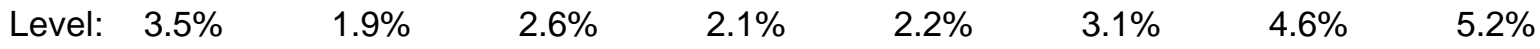

Ph.D.

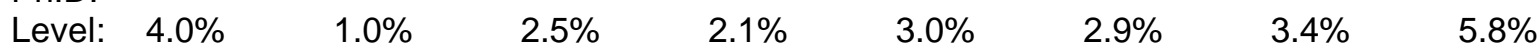


Table 3. Average Starting Salaries: Nuclear Engineering Versus Other Engineering Fields

\begin{tabular}{|c|c|c|c|c|}
\hline & \multicolumn{2}{|c|}{ B.S. Level } & \multicolumn{2}{|c|}{ M.S. Level } \\
\hline & $\begin{array}{l}\text { Average } \\
\text { Salary }\end{array}$ & $\begin{array}{l}\text { '98 to '99 } \\
\% \text { change }\end{array}$ & $\begin{array}{l}\text { Average } \\
\text { Salary }\end{array}$ & $\begin{array}{l}\text { '98 to '99 } \\
\% \text { change }\end{array}$ \\
\hline Nuclear Engineering & $\$ 42,900$ & $6.6 \%$ & $\$ 47,500$ & $5.2 \%$ \\
\hline Chemical Engineering & $\$ 47,100$ & $4.5 \%$ & $\$ 51,700$ & $6.3 \%$ \\
\hline Civil Engineering & $\$ 36,200$ & $2.3 \%$ & $\$ 42,600$ & $2.4 \%$ \\
\hline Computer Engineering & $\$ 45,200$ & $3.0 \%$ & $\$ 58,600$ & $13.5 \%$ \\
\hline Electrical/Electronic Engineering & $\$ 45,100$ & $4.2 \%$ & $\$ 57,600$ & $7.6 \%$ \\
\hline Industrial Engineering & $\$ 43,100$ & $5.2 \%$ & $\$ 50,700$ & $4.8 \%$ \\
\hline Mechanical Engineering & $\$ 43,300$ & $4.9 \%$ & $\$ 51,800$ & $6.4 \%$ \\
\hline
\end{tabular}

\section{PART II. JOB OPPORTUNITIES OUTLOOK FOR 2000-2005}

The outlook for job opportunities for new nuclear engineering graduates for 2000 through 2005 is basically the same as that experienced in the last couple of years.

\section{Primary Factors for Improved Job Opportunities}

- Based on recent enrollment trends, the number of nuclear engineering degrees earned annually is expected to decrease another $10 \%$ over the next couple of years.

- Nuclear engineering majors are expected to continue to find many job opportunities outside of the nuclear energy/nuclear weapons fields. This will be the case as long as the economy continues to grow, thereby keeping demand for engineering skills high.

\section{Secondary Factor for Improved Job Opportunities}

- The number of jobs available for new graduates in the nuclear energy/nuclear weapons fields is expected to remain stable or improve slightly as employment in these fields increases slowly through 2005 and as replacement positions are filled.

Supply of New Graduates Versus Job Openings in Nuclear Energy/Nuclear Weapons Fields

The outlook through 2005 is for the available supply of new nuclear engineering graduates to be somewhat less or, at most, approximately equal to the number of job openings for new graduates in the nuclear energy/nuclear weapons fields. The estimated available supply of new graduates is expected to decline to around 260 to 300 per year while the number of job openings for new graduates is expected to be 275 to 350 per year. While some growth in employment is expected, most of the job opportunities will result from replacement needs due to attrition within the existing workforce. However, as noted above, new graduates in nuclear 
engineering are expected to continue to find many job opportunities outside of the nuclear energy/nuclear weapons fields. This will continue to put pressure on the starting salaries and provide competition to employers in the nuclear energy/nuclear weapons fields.

\section{CONCLUSION}

During the last couple of years, job opportunities for new nuclear engineering graduates have improved substantially from the downturn experienced in the mid 1990s. Currently, the supply of new nuclear engineering graduates is less than the number of job openings especially when the job openings in non-traditional nuclear energy/nuclear weapons fields are considered. The outlook for future job opportunities for new nuclear engineering graduates (through 2005) is for a continuation of the current situation.

This conclusion is based on the following assumptions:

- Over the next year or two, the number of degrees will continue to decline approximately another $10 \%$.

- The economy will continue to grow and provide job opportunities for new graduates outside the nuclear energy/nuclear weapons fields.

- Small employment increases will continue within the nuclear energy/nuclear weapons fields.

\section{ENDNOTES}

1. Labor Market Trends for Nuclear Engineers Through 2005. Oak Ridge Institute for Science and Education. Prepared for the U.S. Department of Energy and the U.S. Nuclear Regulatory Commission. October 1998.

2. The nuclear energy/nuclear weapons fields include: nuclear electric utilities; vendors; consultants; fuel cycle; reactor and instrument design and manufacture; facility architectural design; retrofit, backfit, and betterment; civilian and defense decontamination and decommission; civilian and defense waste management and environmental restoration; nuclear energy research and development; nuclear weapons research, development, and design; nuclear weapons maintenance and production; Department of Energy; and federal, state, and local government agencies.

3. "Salary Information for Health Physicists and Nuclear Engineers, June 1999. Summary Report." Oak Ridge Institute for Science and Education. Prepared for the U.S. Nuclear Regulatory Commission. October 1999.

4. DOE Manpower Assessment Brief. U.S. Department of Energy. No. 44. Prepared by Oak Ridge Institute for Science and Education. May 1999.

5. Information provided by speakers at nuclear engineering education related sessions of the American Nuclear Society meetings, November 1999, Washington, D.C. and May 1997, Orlando Florida.

6. The supply of new graduates available for U.S. civilian employment is defined as the number of new graduates minus the number who continue their studies, obtain a job outside the United States, or enter the active duty military.

7. Salary Survey, July 1999. Vol. 38. Issue 3. National Association of Colleges and Employers. Pages 3 and 4. 
The Oak Ridge Institute for Science and Education (ORISE) was established by the U.S. Department of Energy to undertake national and international programs in education, training, health, and the environment. ORISE and its programs are operated by Oak Ridge Associated Universities (ORAU) under contract with the U.S. Department of Energy. Established in 1946, ORAU is a consortium of 87 colleges and universities. 